\title{
Jet Penetration into a Scaled Microfabricated Stirling Cycle Regenerator
}

\author{
Tracking number: 131604 \\ Liyong Sun ${ }^{1}$, Terrence W. Simon ${ }^{2}$ and Susan C. Mantell ${ }^{3}$ \\ Department of Mechanical Engineering, University of Minnesota, Minneapolis, MN, 55455 \\ Mounir Ibrahim ${ }^{4}$ \\ Department of Mechanical Engineering, Cleveland State University, Cleveland, OH, 44115 \\ David Gedeon $^{5}$ \\ Gedeon Associates, Athens, Ohio, 45701 \\ and \\ Roy Tew ${ }^{6}$ \\ NASA Glenn Research Center, Cleveland, OH, 44135
}

\begin{abstract}
The cooler and heater adjacent to the regenerator of a Stirling cycle engine have tubes or channels which form jets that pass into the regenerator while diffusing within the matrix. An inactive part of the matrix, beyond the cores of these jets, does not participate fully in the heat transfer between the flow of working fluid and the regenerator matrix material, weakening the regenerator's ability to exchange heat with the working fluid. The objective of the present program is to document this effect on the performance of the regenerator and to develop a model for generalizing the results. However, the small scales of actual Stirling regenerator matrices (on the order of tens of microns) make direct measurements of this effect very difficult. As a result, jet spreading within a regenerator matrix has not been characterized well and is poorly understood. Also, modeling is lacking experimental verification. To address this, a large-scale mockup of thirty times actual scale was constructed and operated under conditions that are dynamically similar to the engine operation. Jet penetration with round jets and slot jets into the microfabricated regenerator geometry are then measured by conventional means. The results are compared with those from a study of spreading of round jets within woven screen regenerator for further documentation of the comparative performance of the microfabricated regenerator geometry.
\end{abstract}

\section{Nomenclature}

$$
\begin{aligned}
& =\text { area } \\
& =\text { jet diameter or jet width } \\
& =\text { fraction of inactive matrix material } \\
& =\text { jet length } \\
& =\text { distance along the centerline radius } \\
& =\text { jet center-to-center spacing }
\end{aligned}
$$

\footnotetext{
${ }^{1}$ Research Assistant, Department of Mechanical Engineering, University of Minnesota, AIAA Member.

${ }^{2}$ Professor, Department of Mechanical Engineering, University of Minnesota, AIAA Member.

${ }^{3}$ Professor, Department of Mechanical Engineering, University of Minnesota, AIAA Member.

${ }^{4}$ Professor, Department of Mechanical Engineering, Cleveland State University, AIAA Associate Fellow.

${ }^{5}$ Consultant, Gedeon Associates.

${ }^{6}$ Research Engineer, NASA Glenn Research Center, AIAA Member. 


$\begin{array}{ll}T & =\text { temperature } \\ x & =\text { distance in the axial direction } \\ x_{p} & =\text { jet penetration depth } \\ \theta & =\text { crank angle } \\ \phi & =\text { dimensionless temperature }\end{array}$

\section{Introduction}

$\mathrm{T}$

HE regenerator is the crucial component in the Stirling cycle engine. The regenerator, which obtains thermal energy from the hot working fluid and releases thermal energy to the cold working fluid, recycles the energy internally, allowing the Stirling cycle to achieve high efficiency (as high as $40 \%$ for recent free-piston Stirlng engines). The cooler and heater adjacent to the regenerator of a Stirling engine have tubes or channels, which form jets that pass into the regenerator. Figure 1 shows schematically the jet spreading within the regenerator. The inactive part of the matrix, beyond the edge of the jet, does not participate fully in heat transfer, weakening the regenerator's ability to exchange heat with the working fluid.

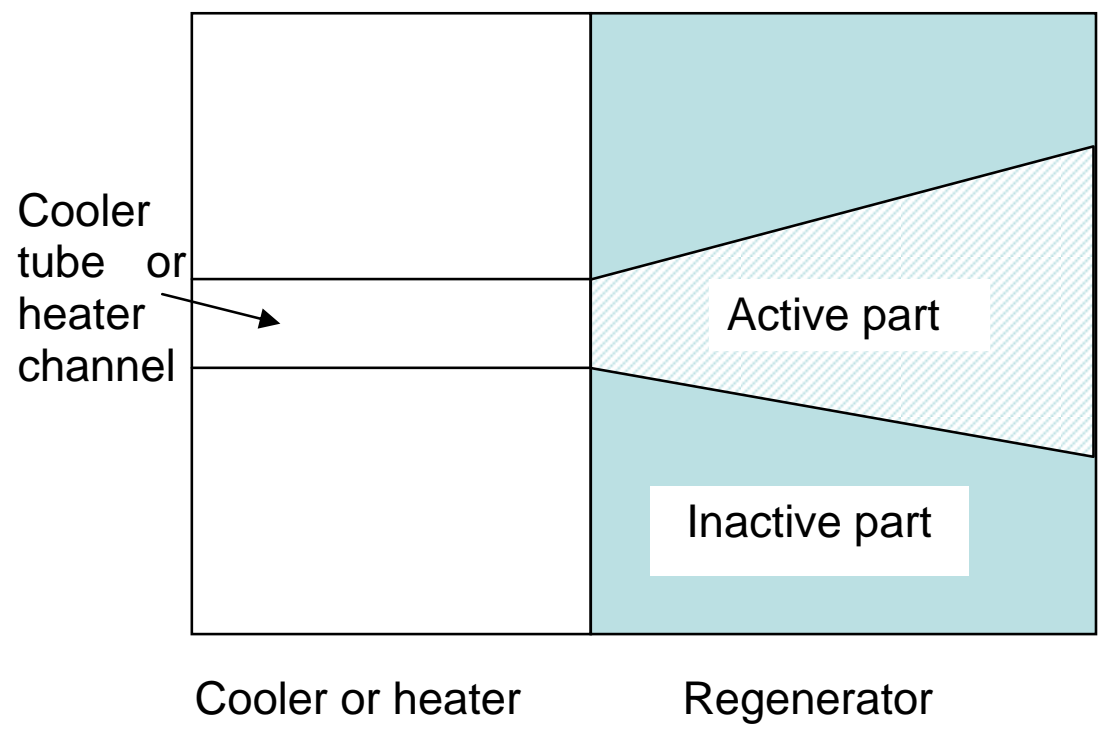

Figure 1. Schematic of jet spreading within a regenerator.

However, the small scale of the Stirling regenerator matrix makes direct measurements of this effect very difficult, and the jet spreading within a regenerator matrix has not been characterized well and is poorly understood. To date, researchers only investigated the jet penetration only in woven screen regenerators; no jet penetration study of any microfabricated regenerator could be found in the literature.

In 1989, using a computer program, Manifest, Gedeon ${ }^{1}$ simulated 2-D jets impinging on Stirling regenerators. The results for the Space Power Research Engine (SPRE) regenerator and a more permeable matrix are shown in Fig. $2 \mathrm{a}$ and $\mathrm{b}$. It is seen that the jets penetrate deeper in the more permeable matrix. Manifest had some limitations. It simulated only a 2-D plane flow, not the actual 3-D flow from the cooler tubes or the heater channels. Also, it simulated steady flow, not oscillating flow. 


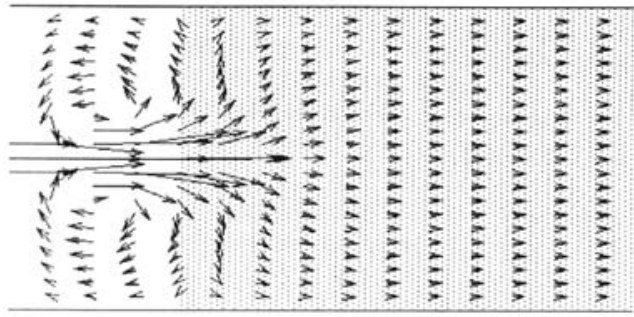

(a)

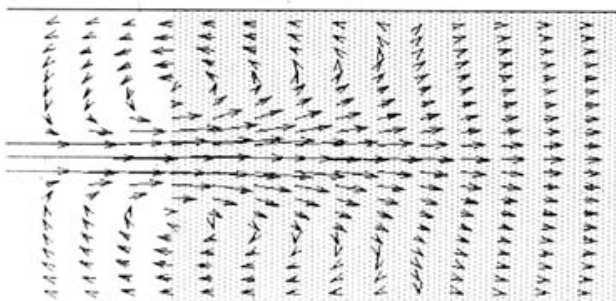

(b)

Figure 2. A laminar jet $(\mathrm{Re}=100)$ impinging on (a) the SPRE regenerator and $(b)$ a more permeable matrix ${ }^{1}$.

Niu et al. ${ }^{2}$ were the first to investigate the jet penetration within a screen regenerator under oscillatory flow conditions. They measured the distances into the regenerator required for the jets to merge completely and the fraction of the matrix that does not participate fully in heat transfer. Also, they found that the effect of regeneratorto-cooler plenum spacing on how the flow enters the matrix is weak.

This report discusses results of an experimental investigation of round- and slot-jet penetration into a large-scale microfabricated involute-foil regenerator.

\section{Experiments}

\section{A. Experimental Facility}

Figure 3 shows a schematic of the large-scale involute-foil test facility. The main components of the facility are the oscillatory-flow generator, a cooler, two transition pieces (one on each end of the regenerator), a jet generator, ten Large Scale Mock Up (LSMU) plates, an electrical heating coil, and an isolation duct. The oscillatory-flow generator, using a Scotch-yoke mechanism, produces precise sinusoidal movement of the piston with a zero-mean velocity. Figure 4 shows the schematic of the oscillatory flow generator, the generator details were given in a NASA report by Seume et al. ${ }^{3}$. In this experiment, the piston stroke is $178 \mathrm{~mm}$, the piston diameter is $216 \mathrm{~mm}$, and the frequency is $0.2 \mathrm{~Hz}$, selected to match the Reynolds number and the Valensi number of the microfabricated regenerator in the pattern engine ${ }^{4}$.

The cooler is a compact heat exchanger such as that used to heat the passenger compartment of a car (called a heater core). The transition piece is for transitioning from a round tube with inner diameter of $0.19 \mathrm{~m}$ ( 7.5 inches) to a sector of an annulus. It consists of 9 layers (near the LSMU plates) having the sector-of-an-annulus shape opening and one layer having a round opening. The thickness of each layer is $12.7 \mathrm{~mm}(0.5 \mathrm{inch})$. The material of the transition layer is black foam, an insulation material. Screen material is sandwiched between layers to provide the flow diffusion. The screen wire diameter is $0.305 \mathrm{~mm}$ ( 0.012 inches). The screen is made of aluminum and the mesh size is 289 .

The jet generator is to simulate the cooler or heater adjacent to the regenerator in a Stirling engine. The geometries of the round jets and slot jets for proper scaling were provided by David Gedeon ${ }^{5}$. They are representative of modern Stirling engines being developed for NASA space power applications. The geometry of the round jet generator and the plenum which is a sector of an annulus in shape is shown in Fig. 5. Round holes are arranged in an equilateral triangle pattern. The hole diameter is $20 \mathrm{~mm}$ and the center-to-center spacing is $40 \mathrm{~mm}$. The jet generator is $30.5 \mathrm{~cm}$ (12 inches) long giving a hole L/D ratio of 15.2 .

Figure 6 shows the slot-jet generator and the plenum which is also a sector of an annulus in shape. The slot channels are separated by the fins in the slot jet generator. The channel width is $8.5 \mathrm{~mm}$ and the fin thickness is 23 $\mathrm{mm}$. The jet generator is $30.5 \mathrm{~cm}$ (12 inches) long.

A LSMU plate is a large-scale mockup of thirty times actual scale of the microfabricated regenerator. The microfabricated regenerator is of an annular design that cannot be scaled up in its entirety to a factor of 30 and still be operational in our oscillatory flow facility. Thus, only a $30^{\circ}$ sector of an annulus is chosen for modeling. The plate thickness is $7.94 \mathrm{~mm}$. The geometry details were given in a thesis ${ }^{4}$.

The electrical heating element is made of four electrically-heated screen layers. The isolation duct is a long, open tube. It has active mixing to isolate the flow features of the experiment from the features of the flow entering from the room. There is a plenum between the cold-end transition piece and the LSMU plates which allows a single hot- 
wire probe, with a support tube diameter of $4.57 \mathrm{~mm}$, to be inserted into the plenum for taking velocity measurements. The thickness of the plenum is $5 \mathrm{~mm}$. A spacer consisting of two $0.76 \mathrm{~mm}(0.030$ inch $)$ thick stainless steel sheets is inserted between two adjacent LSMU plates to allow the thermocouple wire used to take temperature profiles to pass through the test matrix. The opening of the spacer, which is the gap between the two stainless steel sheets, is $0.51 \mathrm{~mm}(0.020$ inch) wide. The spacer can be moved to any axial location within the LSMU matrix, allowing temperature documentation at various axial locations.

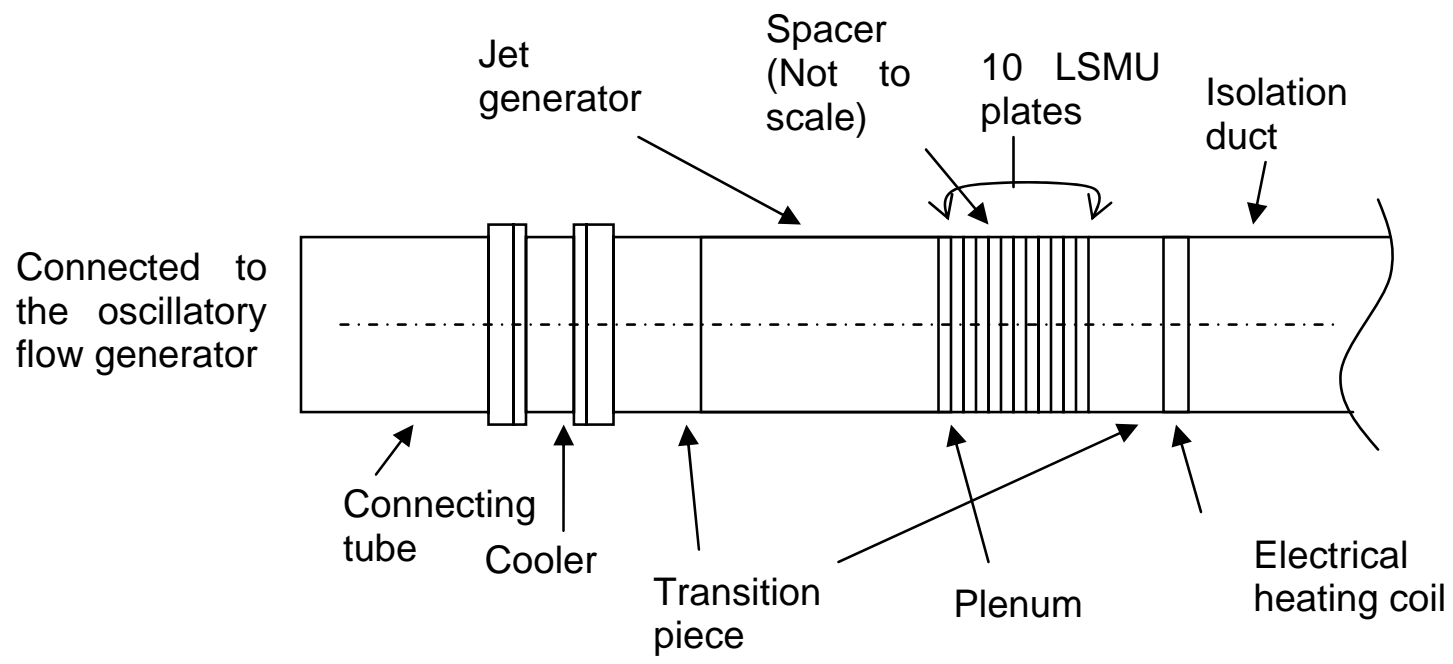

Figure 3. The schematic of the test facility.

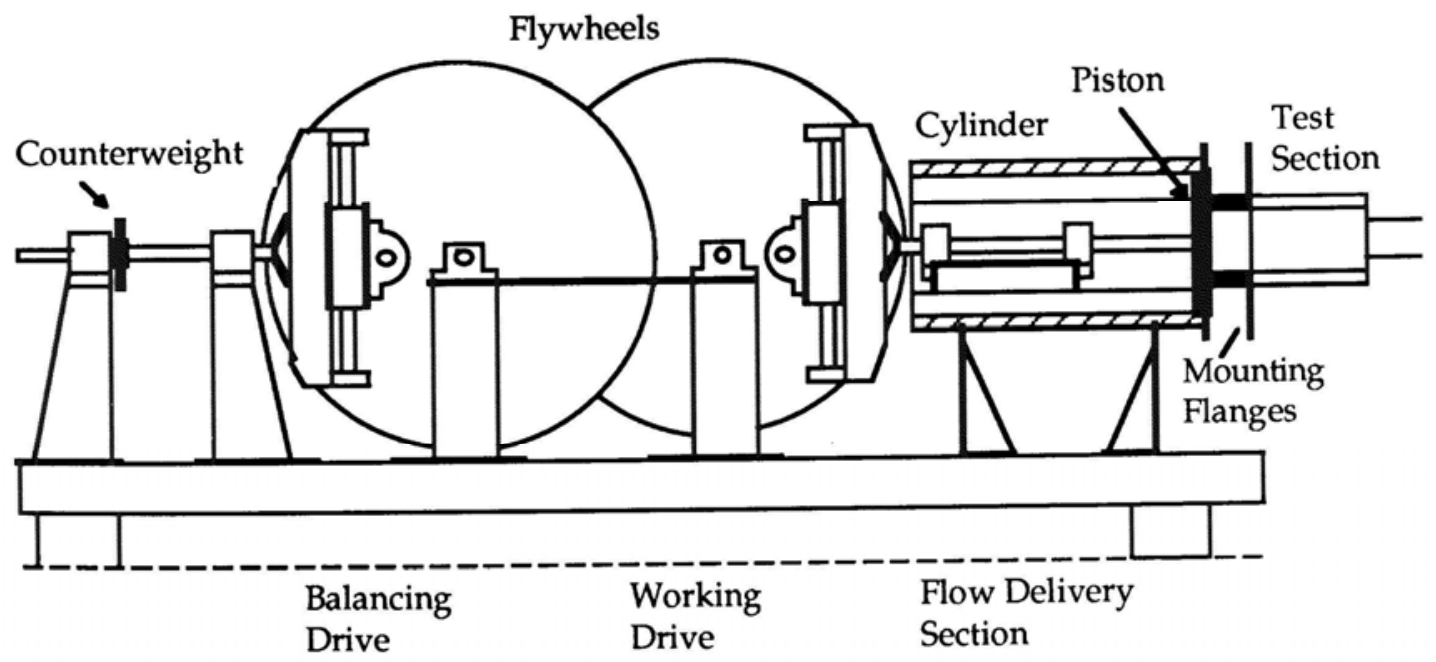

Figure 4. Schematic of the oscillatory flow generator ${ }^{3}$. 


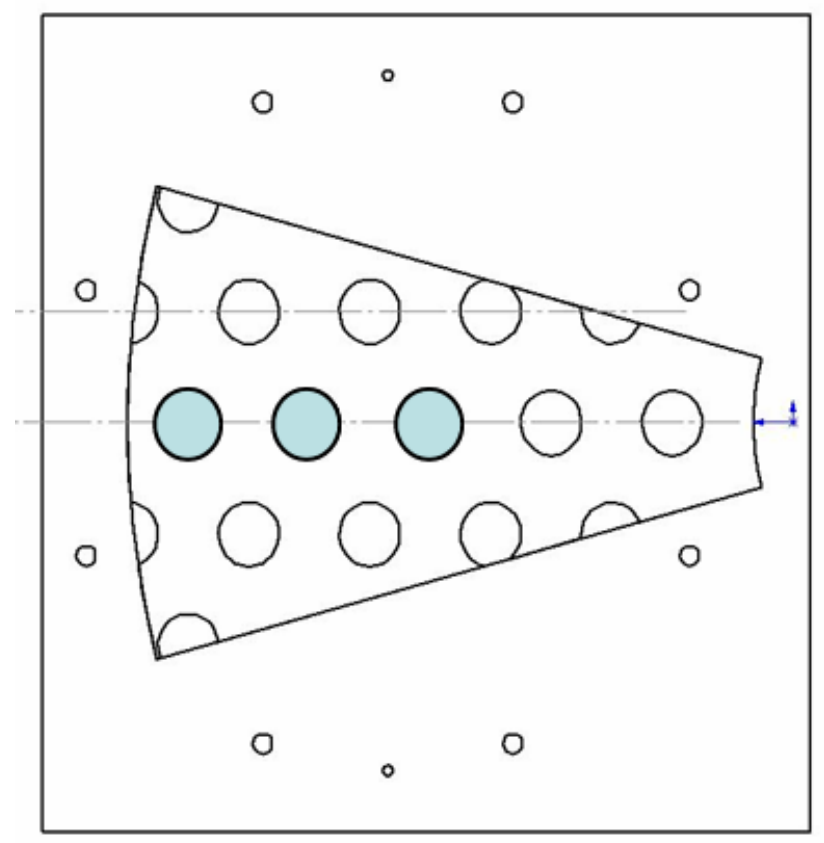

Figure 5. The round jet generator and the plenum shape, a sector of an annulus. The center jet of the three colored (or shaded) jet is the primary jet.

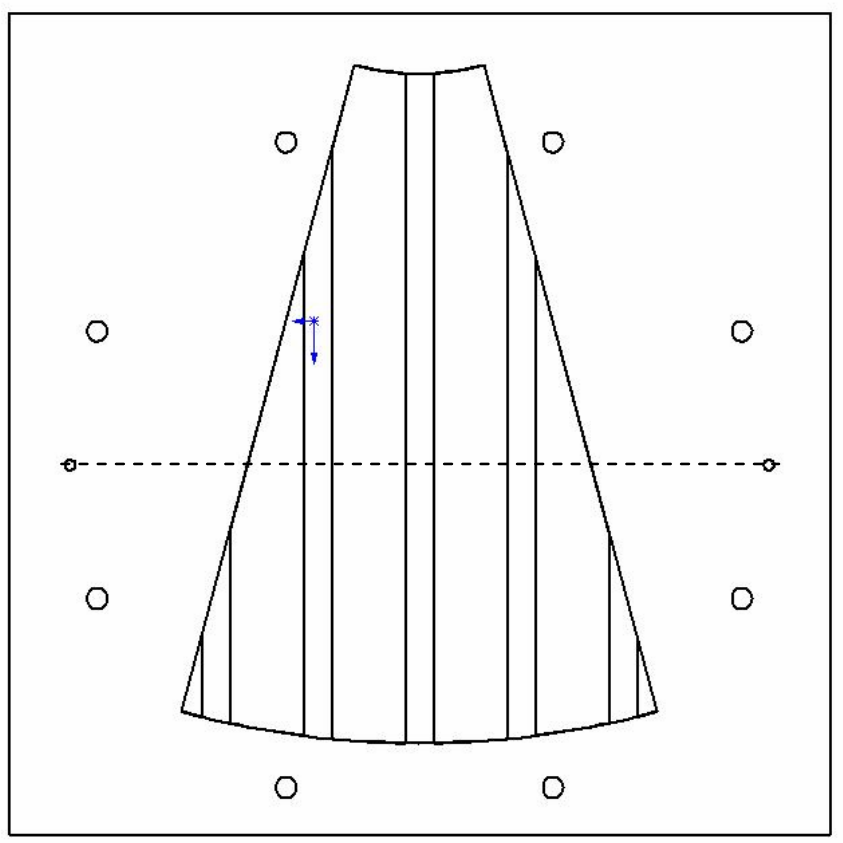

Figure 6. The slot jet generator and the plenum shape, a sector of an annulus.

\section{B. Instrumentation and Data Acquisition}

A hot wire sensor (TSI 1210-T1.5) with an anemometer (TSI IFA 100) is used to measure the velocities within the plenum between the jet generator and the LSMU regenerator plates. The voltage readings of the anemometer are input to the multimeter (Agilent 34401A) and then collected by the computer. The multimeter is connected to the computer by IEEE488 cable. The hot-wire probe is driven by the stepper motor to move horizontally within the plenum. 
Thermocouples of type $\mathrm{E}$ with a diameter of $76 \mu \mathrm{m}$ ( 3 mils) are used for unsteady temperature measurements within the LSMU plate test section. The time constant of the thermocouple is $0.05 \mathrm{sec}$, which means that the thermocouple can sufficiently quickly respond to changes in flow temperature. The thermocouple measuring the temperature within the LSMU matrix is mounted on a stepper-motor-driven rail so that it can be traversed inside the spacer and between two LSMU plates. The spacer can be moved to other axial locations within the LSMU matrix, allowing temperature documentation at various axial locations. The temperatures within the LSMU matrix, $T(x, r, \theta)$, are presented as functions of $x$, the distance in the axial direction; $r$, the distance along the centerline radius; and $\theta$, the crank angle. One stationary thermocouple is located at one end of the jet generator and adjacent to the plenum. It is for measuring the cold-end temperature, $T_{c}(\theta)$. Another stationary thermocouple is located at the end of the transition piece which is adjacent to the LSMU plates. It is for measuring the hot-end temperature, $T_{h}(\theta)$. At each location, these three temperatures are taken at a sampling frequency of $500 \mathrm{~Hz}$ for 50 cycles. To eliminate temperature drift, a dimensionless temperature is calculated as:

$$
\phi(x, r, \theta)=\frac{T(x, r, \theta)-T_{c}}{T_{h}-T_{c}}
$$

The cold-end temperature, $T_{c}(\theta)$, is averaged over the portion of one cycle when the flow is passing from the jet generator to the LSMU-regenerator plates. This gives an average temperature, $T_{c}$, for each cycle. The hot-end temperature, $T_{h}(\theta)$, is averaged over the portion of one cycle when the flow is passing from the heater to the LSMU regenerator plates. This gives an average temperature, $T_{h}$, for one cycle. The dimensionless temperature $\phi(x, r, \theta)$ is calculated for each reading of the cycle. Averages of $\phi(x, r, \theta)$ are taken over an ensemble of 50 cycles.

The voltages generated by the thermocouple which is traversing between the LSMU plates are amplified by a Preston 8300 XWB amplifier. The voltages generated by the thermocouples at the hot and the cold end of the LSMU plates are amplified by DATAFORTH SCM5B30 amplifiers. Measurements are taken over 50 cycles to get ensemble-averaged values resolved in position within the oscillation period. All the signals are digitized with 16-bit A/D converters (IOTECH ADC488) and are bused to a computer. The thermocouples are calibrated by a NIST traceable certified thermometer with resolution of $0.1{ }^{\circ} \mathrm{C}$. The uncertainty of the temperature measurement is 0.05 ${ }^{\circ} \mathrm{C}$.

\section{Experimental Results}

\section{A. Jet-to-jet Uniformity}

To verify that the flow was uniformly distributed in the round-jet generator and the slot-jet generator under oscillatory-flow conditions, the velocities within the plenum between the jet generator and the LSMU regenerator plates were measured. Results are given versus time within a oscillation cycle based upon an ensemble average of 50 cycles. For the round-jets experiment, the hot-wire probe is driven by the stepper motor to move horizontally along a line which passes through the centerlines of the three holes highlighted in Fig. 5. For the slot-jets experiment, the hot-wire probe moves horizontally along a line which passes through the center of the jet generator, normal to the slots (shown as the dashed line in Fig. 6). Each velocity measurement is taken at a sampling frequency of $500 \mathrm{~Hz}$ for 50 cycles. Velocity profiles taken during the blowing half of the cycle, when the flow is passing from the round-jet generator to the LSMU plates, are shown in Fig. 7. The origin of the horizontal axis is the center of the center jet. Velocity profiles show that the jets from the three round channels are very similar to one another. This confirms that when the center jet is interrogated, the data are representative of data for flow from all interior jets. Velocity profiles taken during the blowing half of the cycle, when the flow is passing from the slot-jet generator to the LSMU plates, are shown in Fig. 8. The origin of the horizontal axis is the center of the center jet. Velocity profiles show that the jets from the three slot channels shown are very similar to one another. 


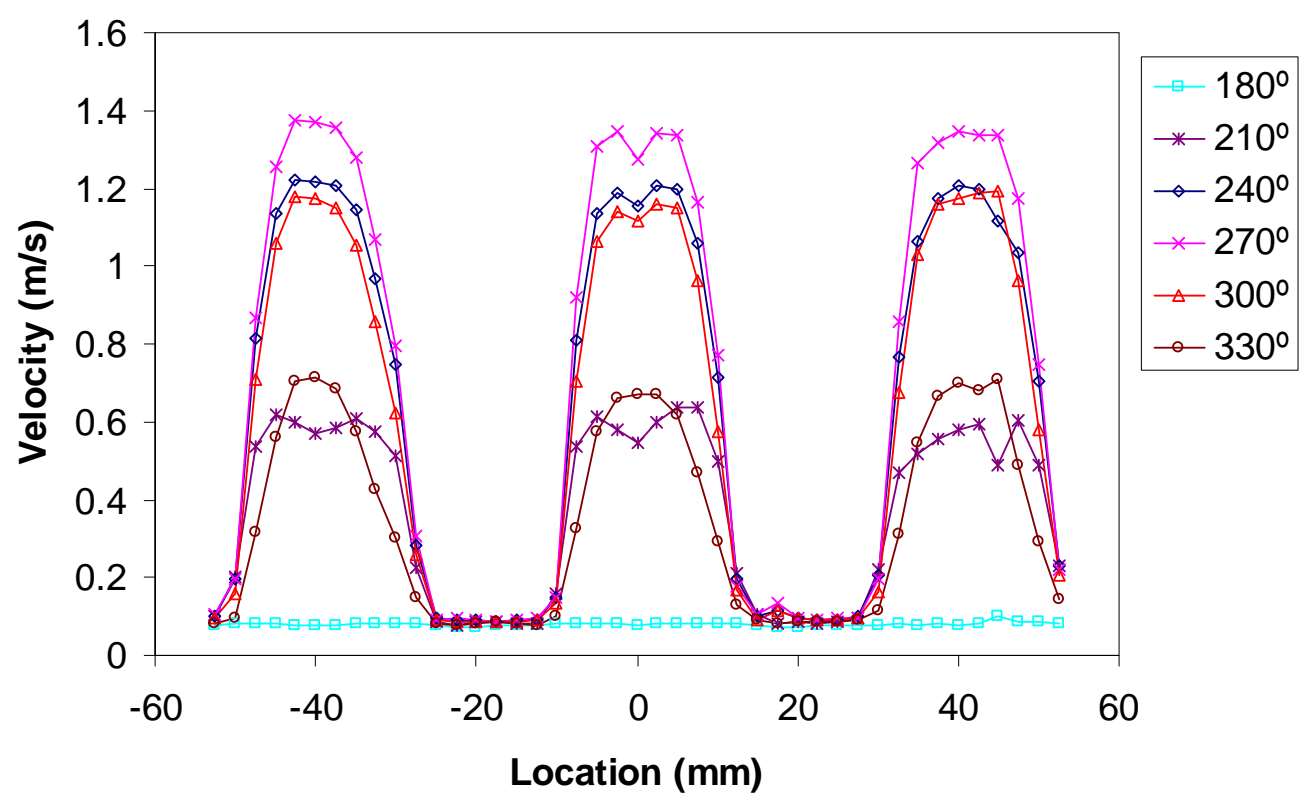

Figure 7. Velocity profiles during the blowing half of the cycle, when the flow is passing from the roundjet generator to the LSMU plates. The origin of the horizontal axis is the center of the center jet.

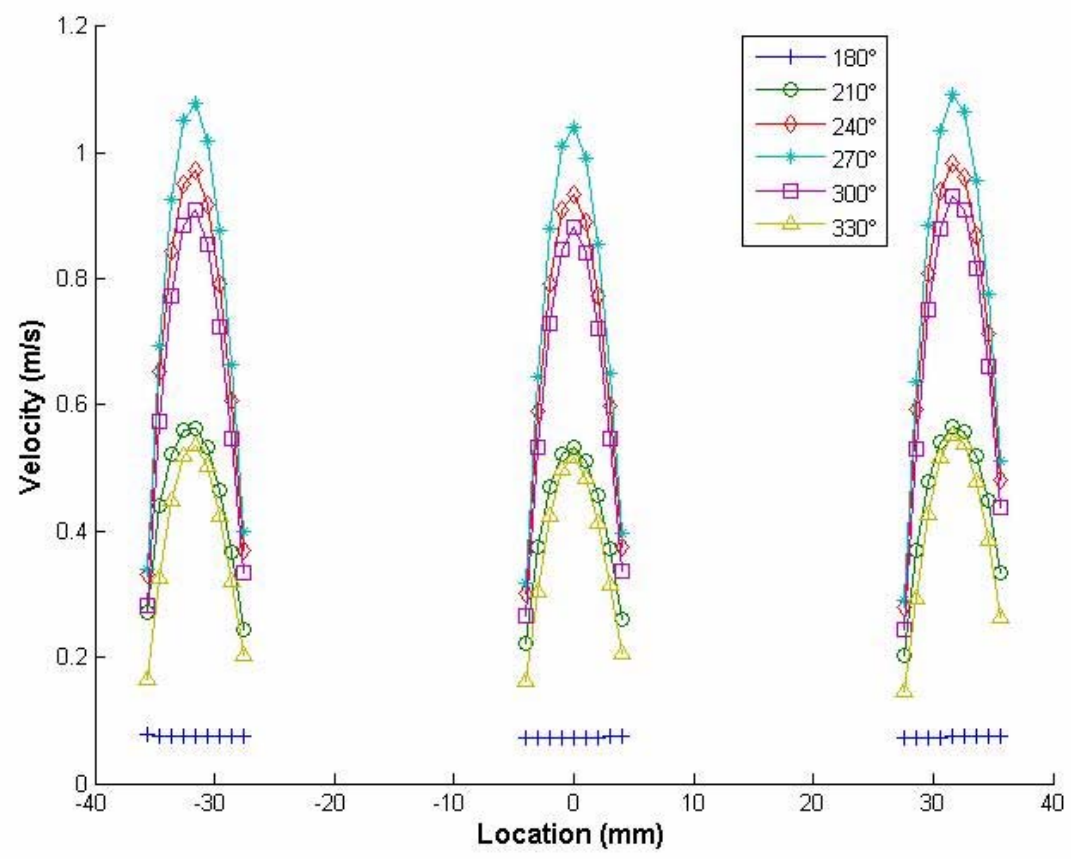

Figure 8. Velocity profiles during the blowing half of the cycle, when the flow is passing from the slot-jet generator to the LSMU plates. The origin of the horizontal axis is the center of the center jet.

\section{B. Jet Penetration}

1. The Round Jet

The dimensionless temperatures at six axial locations have been measured. The six locations are: between the plenum on the jet generator side and the first LSMU plate, between plates 2 and 3, between plates 3 and 4, between 
plates 5 and 6, between plates 8 and 9, and after plate 10. The dimensionless temperature profiles are shown in Figs. 9 through 14.

During the blowing half of the cycle, when the flow is passing from the jet generator to the LSMU plates, the crank angle changes from $180^{\circ}$ to $360^{\circ}$. Three cold jets, which are distinguished from the rest of the region, can be seen in Fig. 9. Figure 13 shows that the jet edges are nearly imperceptible between plates 8 and 9. The jet penetration depth is about the thickness of 8 LSMU plates, which is $63.5 \mathrm{~mm}$. The hydraulic diameter of the LSMU plates is $4.872 \mathrm{~mm}$, so the jet penetration depth is about 13 times the hydraulic diameter. The depth of jet penetration into a screen regenerator is 3.33 times the hydraulic diameter of the screen regenerator ${ }^{2}$. A movie of the jet penetration was generated and can be obtained from the author. In Figs. 13 and 14, one can see an effect of the boundary of the test section at the larger radius of Fig. 5 beginning to influence the temperature data for $r>35 \mathrm{~mm}$.

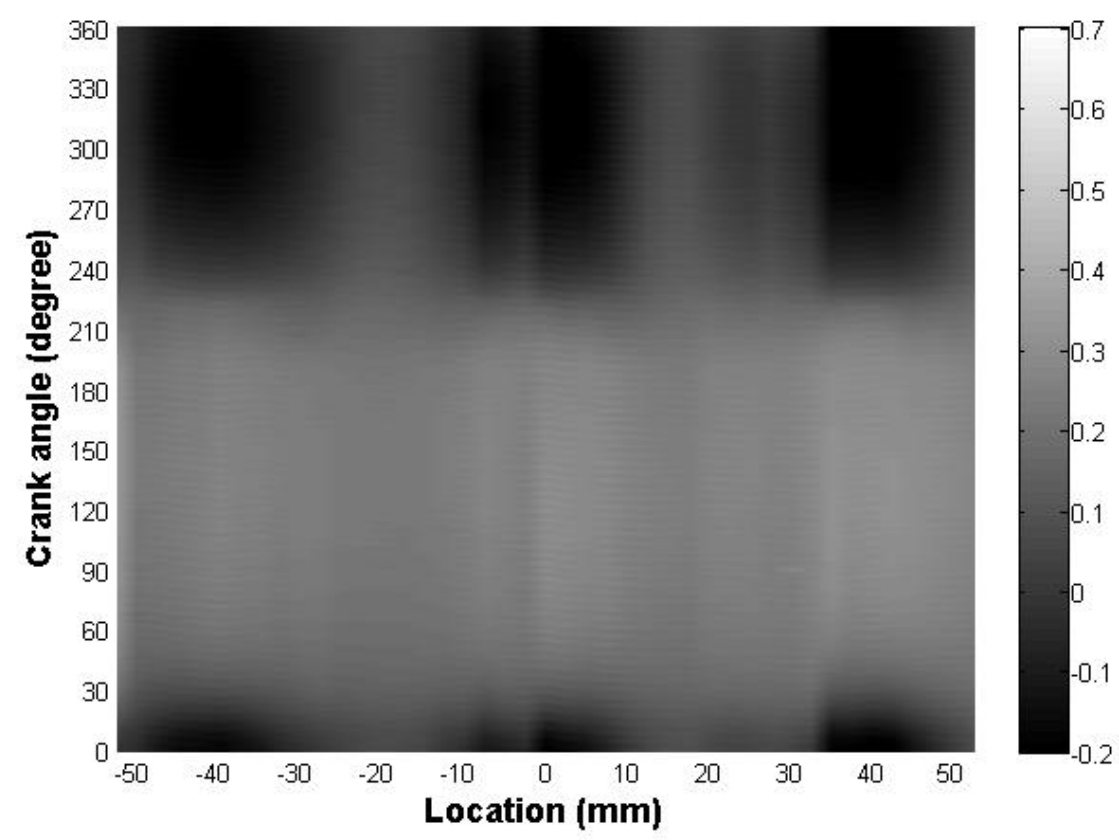

Figure 9. Dimensionless temperature profiles between the plenum and the first LSMU plate. The origin of the horizontal axis is the center of the center jet. Neighboring jets are centered at $\mathbf{- 4 0} \mathbf{~ m m}$ (the one at the larger radius of Fig. 5) and $40 \mathrm{~mm}$. 


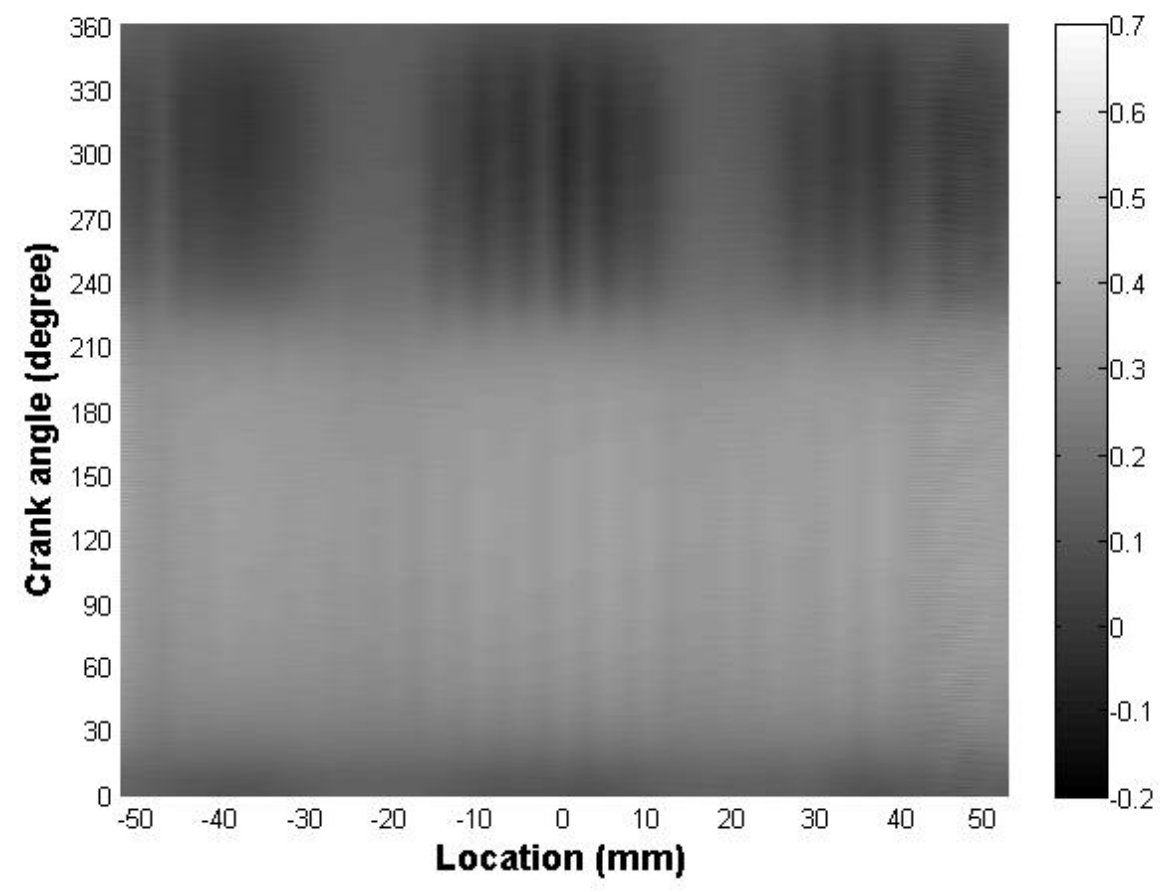

Figure 10. Dimensionless temperature profiles in the middle of the LSMU plates, between plates 2 and 3. The origin of the horizontal axis is the center of the center jet.

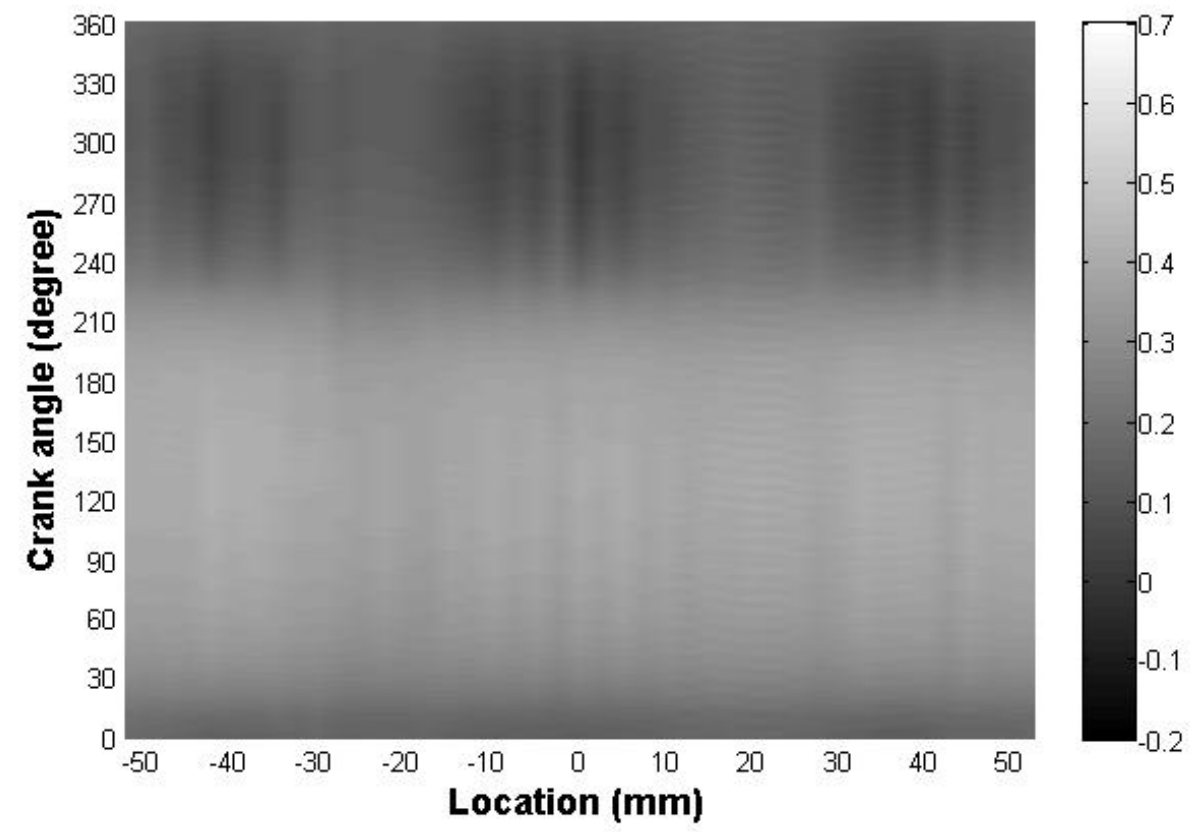

Figure 11. Dimensionless temperature profiles in the middle of the LSMU plates, between plates 3 and 4. The origin of the horizontal axis is the center of the center jet. 


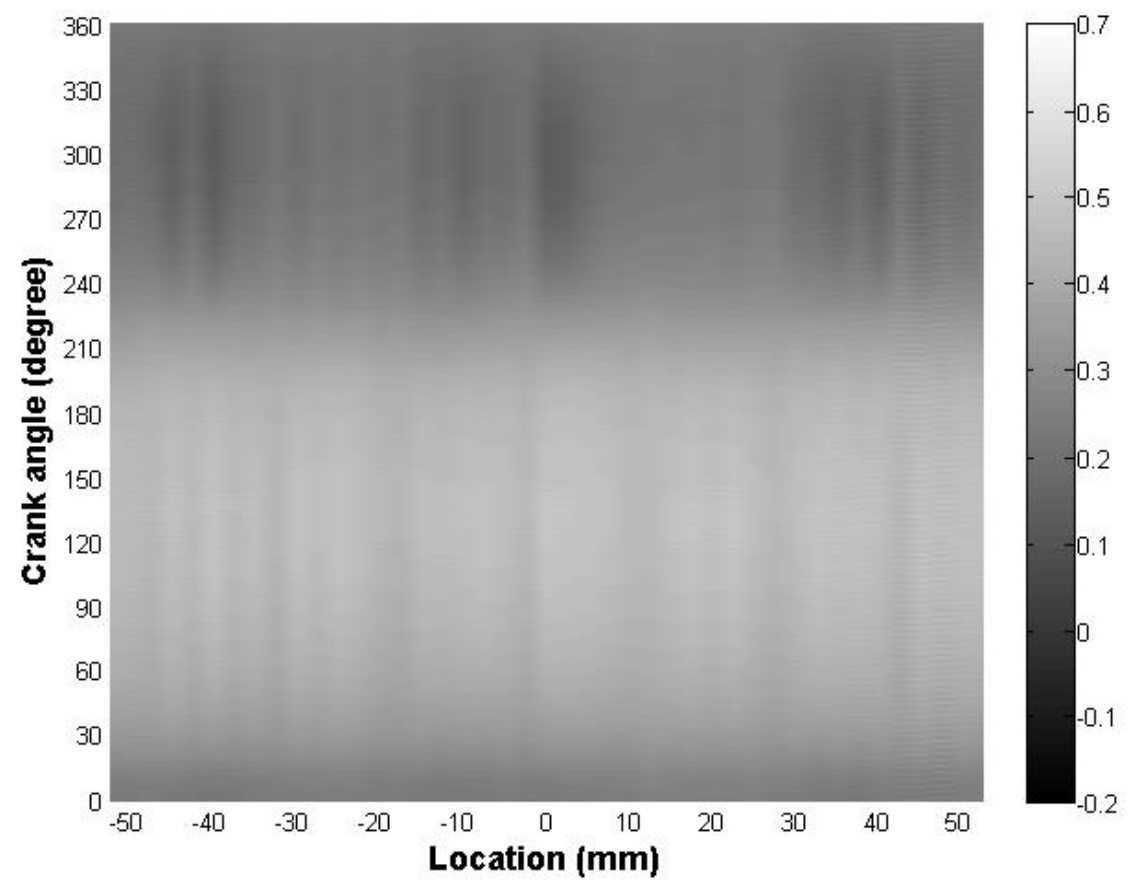

Figure 12. Dimensionless temperature profiles in the middle of the LSMU plates, between plates 5 and 6. The origin of the horizontal axis is the center of the center jet.

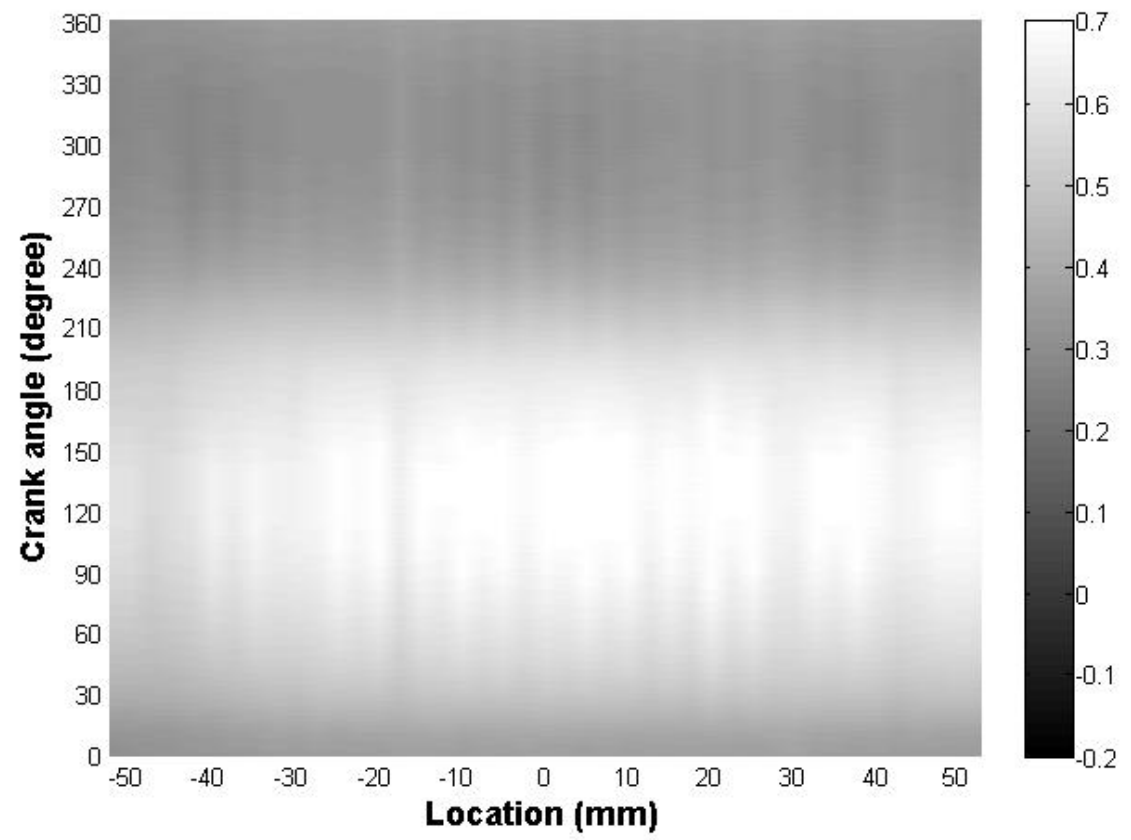

Figure 13. Dimensionless temperature profiles in the middle of the LSMU plates, between plates 8 and 9. The origin of the horizontal axis is the center of the center jet. 


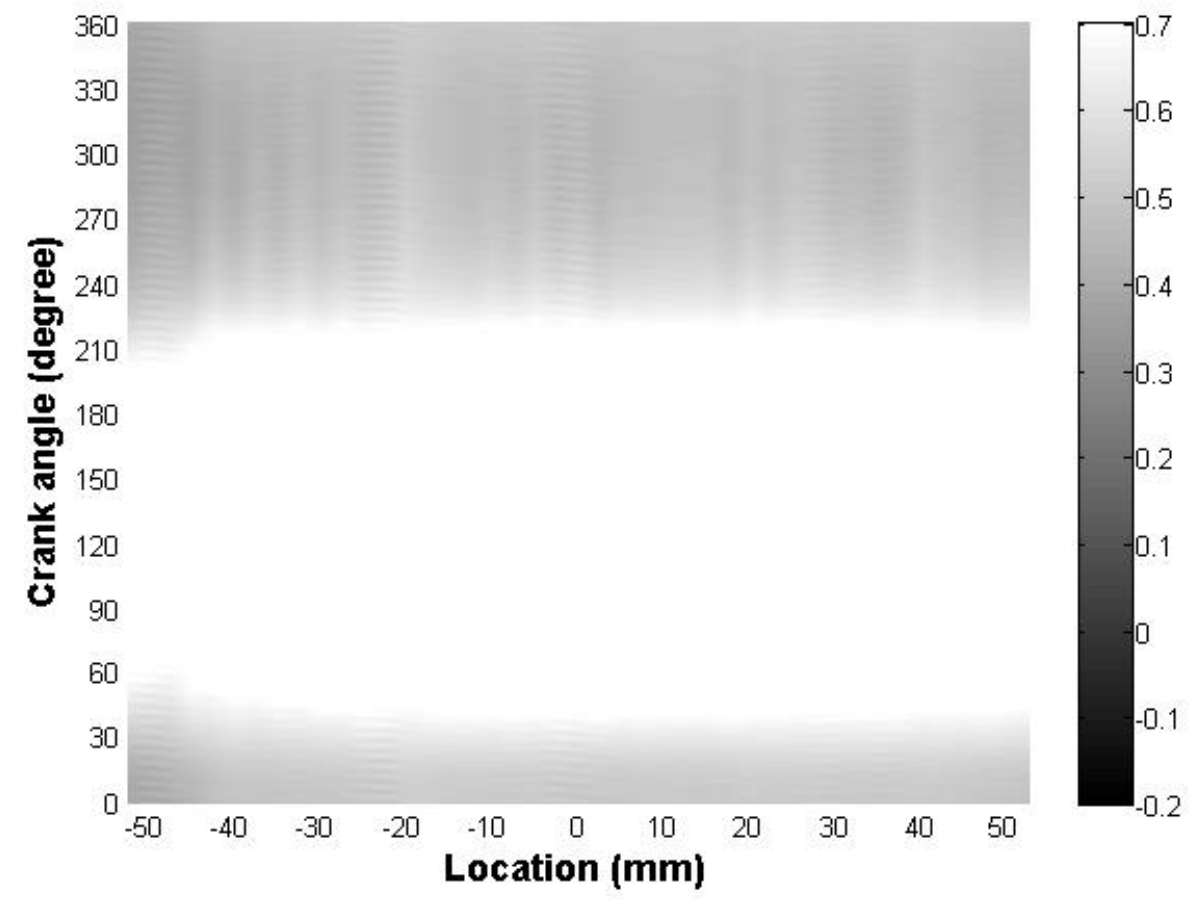

Figure 14. Dimensionless temperature profiles after $10 \mathrm{LSMU}$ plates. The origin of the horizontal axis is

\section{The Slot Jet} the center of the center jet.

Dimensionless temperatures at five axial locations were measured. The five locations were: between the plenum on the jet generator side and the first LSMU plate, between plates 3 and 4, between plates 5 and 6 , between plates 6 and 7, and between plates 8 and 9. The dimensionless temperature profiles are shown in Figs. 15 through 19. A movie of the jet penetration was generated and can be obtained from the author.

During the blowing half of the cycle, when the flow is passing from the jet generator to the LSMU plates, the crank angle changes from $180^{\circ}$ to $360^{\circ}$. Three cold jets, which are distinguished from the rest of the region, can be seen in Fig. 15 (between the plenum and the first LSMU plate). Figure 18 shows that the jet edges are nearly imperceptible between plates 6 and 7. The jet penetration depth is about the thickness of 6 LSMU plates, which is $47.6 \mathrm{~mm}$. The hydraulic diameter of the LSMU plates is $4.872 \mathrm{~mm}$ so the jet penetration depth is about 10 times the hydraulic diameter. 


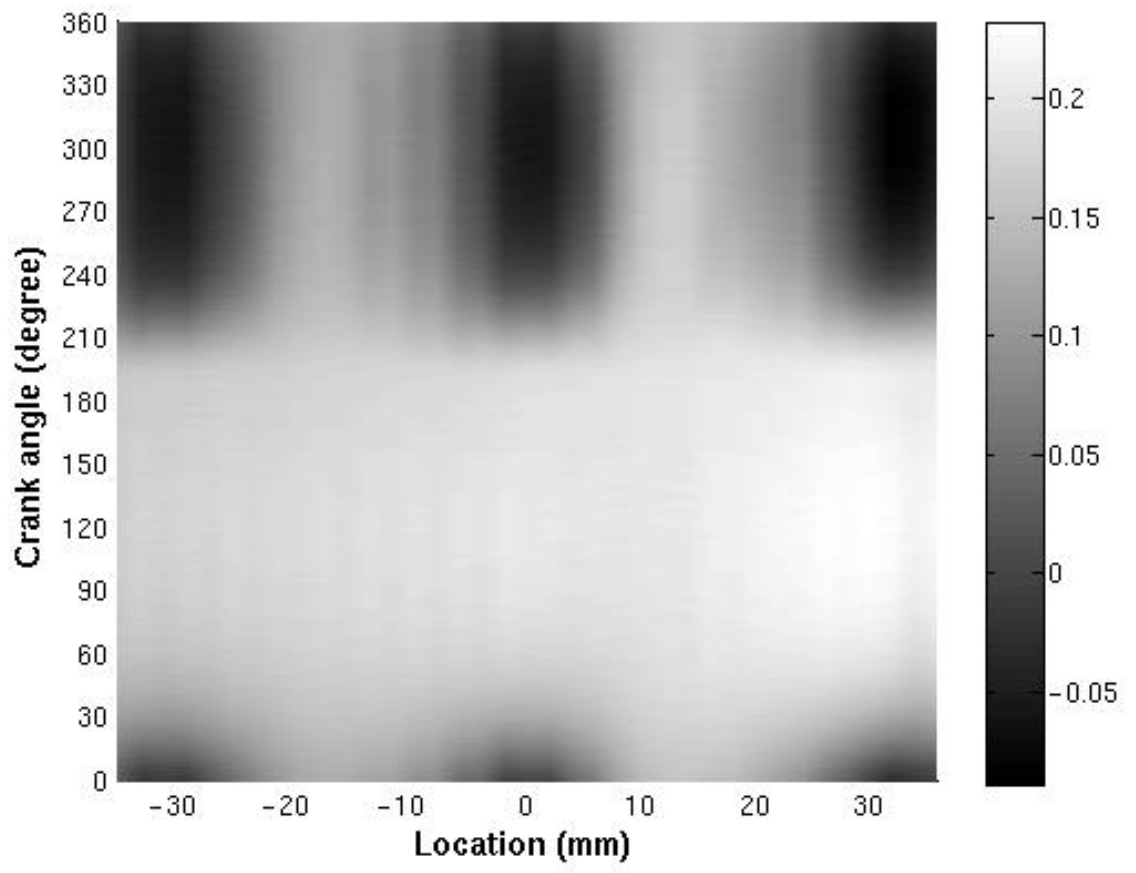

Figure 15. Dimensionless temperature profiles between the plenum and the first LSMU plate. The origin of the horizontal axis is the center of the center jet. Neighboring jets are centered at $\mathbf{- 3 1 . 5} \mathbf{~ m m}$ (left side of Fig. 6) and $31.5 \mathrm{~mm}$.

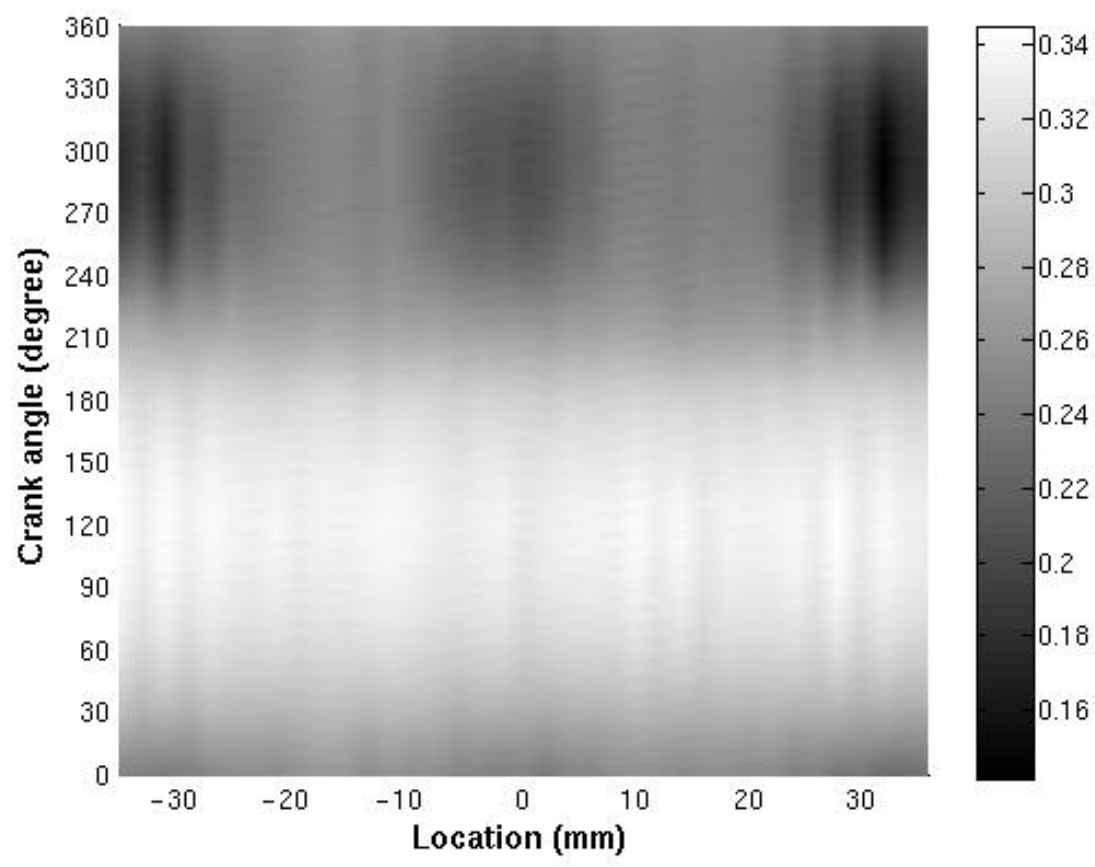

Figure 16. Dimensionless temperature profiles in the middle of the LSMU plates, between plates 3 and 4. The origin of the horizontal axis is the center of the center jet. 


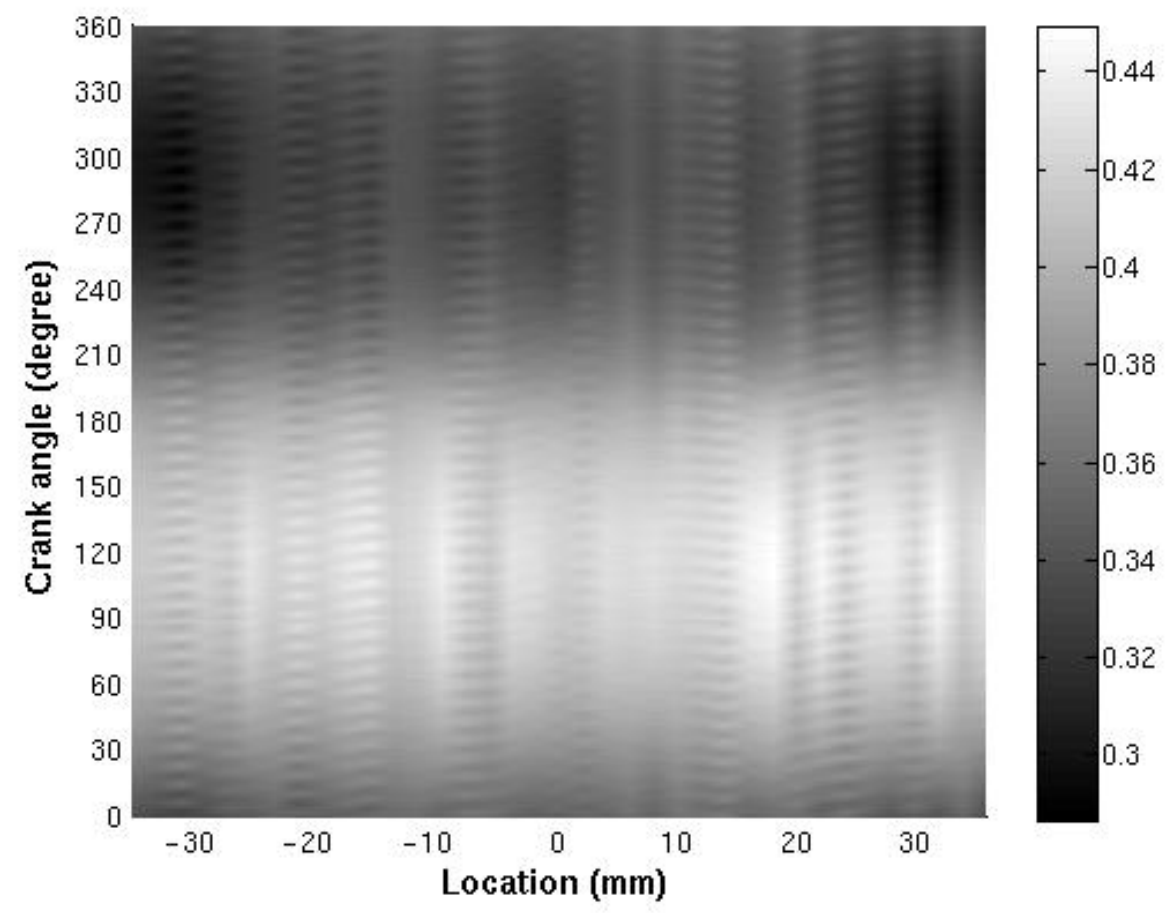

Figure 17. Dimensionless temperature profiles in the middle of the LSMU plates, between plates 5 and 6. The origin of the horizontal axis is the center of the center jet.

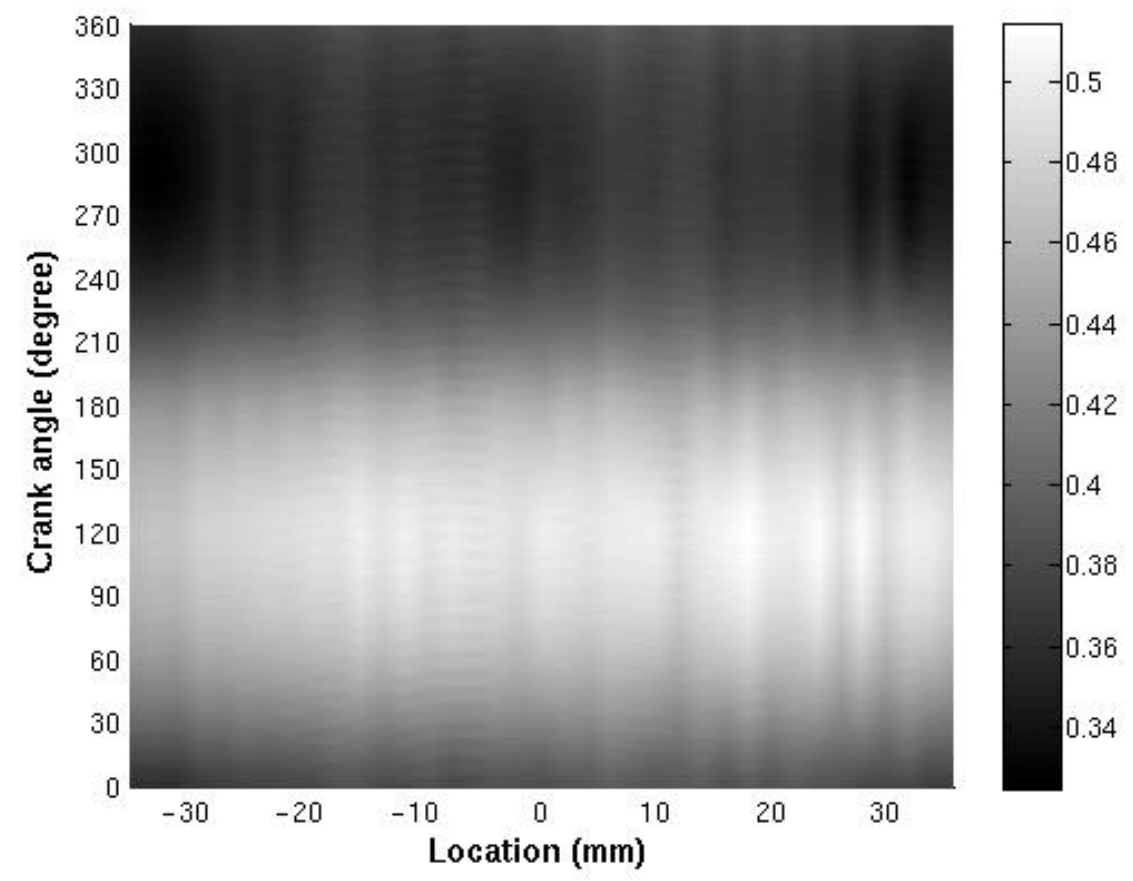

Figure 18. Dimensionless temperature profiles in the middle of the LSMU plates, between plates 6 and 7. The origin of the horizontal axis is the center of the center jet. 


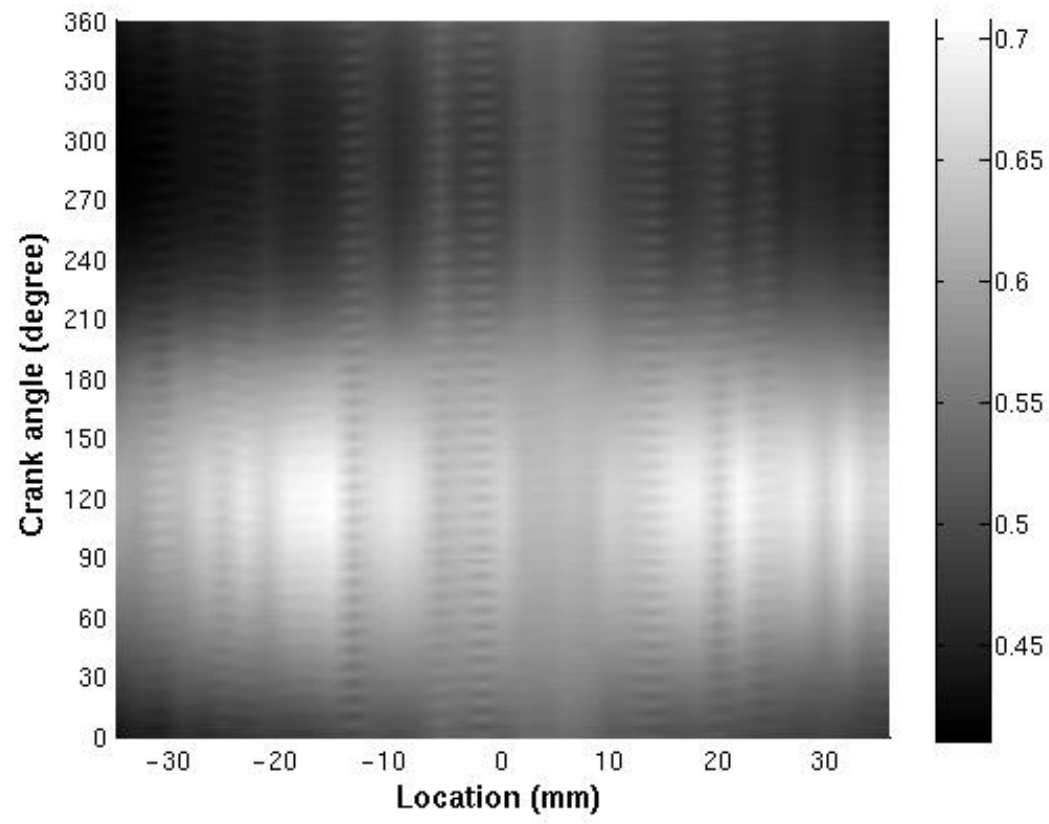

Figure 19. Dimensionless temperature profiles in the middle of the LSMU plates, between plates 8 and 9. The origin of the horizontal axis is the center of the center jet.

\section{The Fraction of Inactive Matrix Material}

The center jet's edge, as the jet expands along the axial flow direction, is defined as the point at which the dimensionless temperature is the average of the maximum and the minimum dimensionless temperatures found in traversing across the jet--at a certain axial location and a certain crank angle:

$$
\phi(x, b / 2, \theta)=\frac{1}{2}\left(\phi_{\max }(x, \theta)+\phi_{\min }(x, \theta)\right)
$$

where $\pm b / 2$ represents the two edges of the jet, with the center of the jet at the origin. Throughout the blowing half cycle, this jet diameter remains almost invariant with crank angle. The dimensionless temperature at $270^{\circ}$ crank angle is chosen to evaluate the jet growth. Figure 20 shows the jet growth along the axial direction. For the round jet, the jet edges are difficult to identify between plates 5 and 6 and the jet width there is extrapolated. For the slot jet, the jet edges are difficult to identify between plates 6 and 7 and the jet width there is found by extrapolation. 


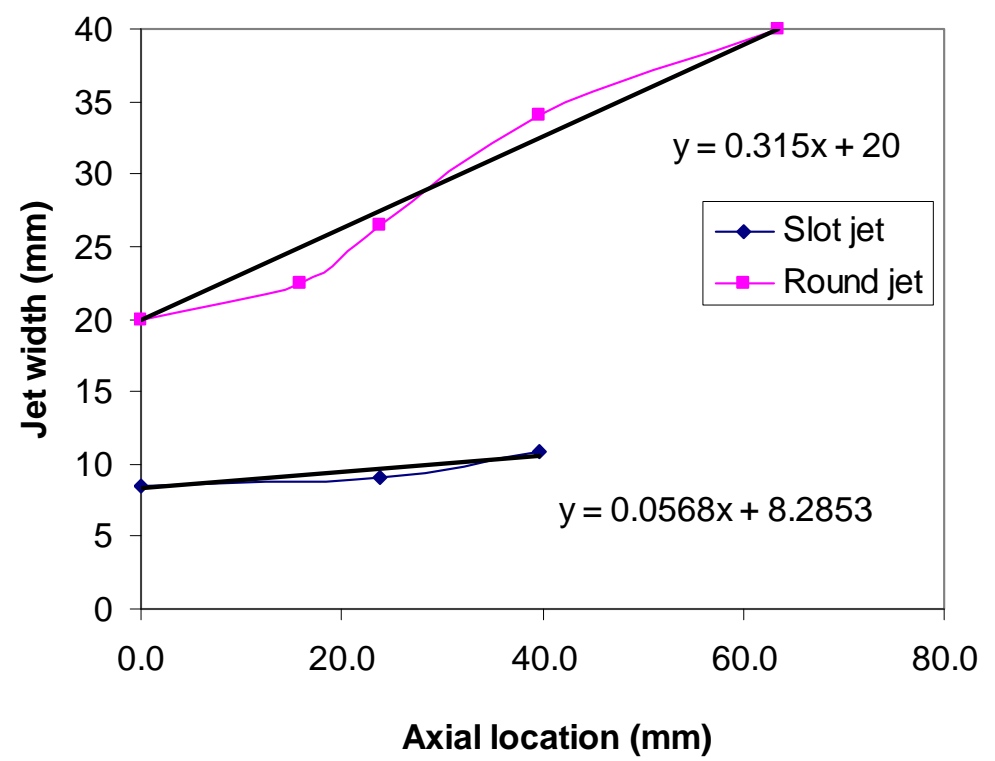

Figure 20. Jet width of slot jet and round jet at crank angle $270^{\circ}$. The solid, straight line is the fitting curve.

Figure 21 shows the jet penetration in the matrix and the jet penetration depth $x_{p}$. The fraction of inactive matrix material is the fraction of matrix material that is not participating fully in thermal exchange with the working medium over the jet penetration depth, $x_{p}$. The fitting equation of Fig. 20 can be used to get the jet diameter, $b(x)$, over $0<x / d_{h}<13$ for the LSMU plates. For one round jet, the corresponding matrix area is a hexagon with side length of $23.1 \mathrm{~mm}$, which is shown in Fig. 22. The area of the hexagon is $A_{j}$. For the round jet, the fraction of inactive matrix material is calculated by

$$
F=\frac{1}{x_{p}} \int_{0}^{x_{p}} \frac{\left[A_{j}-\frac{\pi b(x)^{2}}{4}\right]}{A_{j}} d x
$$

A value of $47 \%$ is found for the LSMU plates with the round jet generator. One can compute an equivalent depth of inactive matrix by multiplying $x_{p} / d_{h}$ by $\mathrm{F}: x_{p} / d_{h} \cdot \mathrm{F}=13 \times 0.47=6.11$. Thus, matrix material to a depth of 6.11 hydraulic diameters is identified as inactive. 


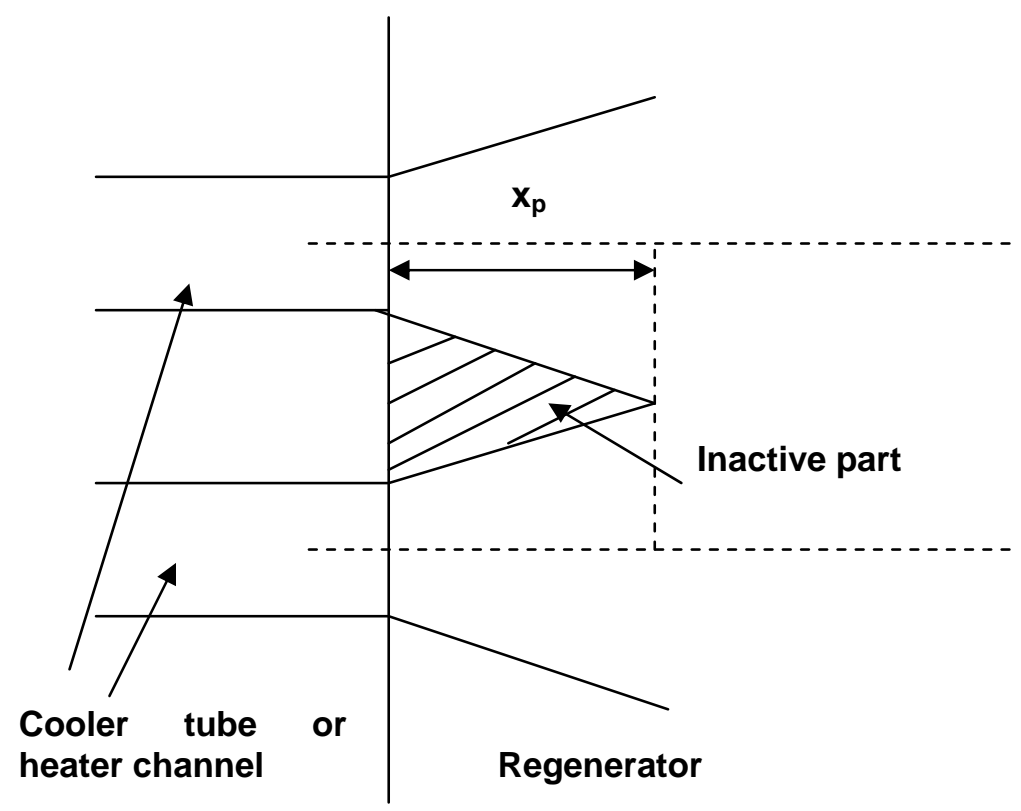

Figure 21. Jet penetration in the matrix.

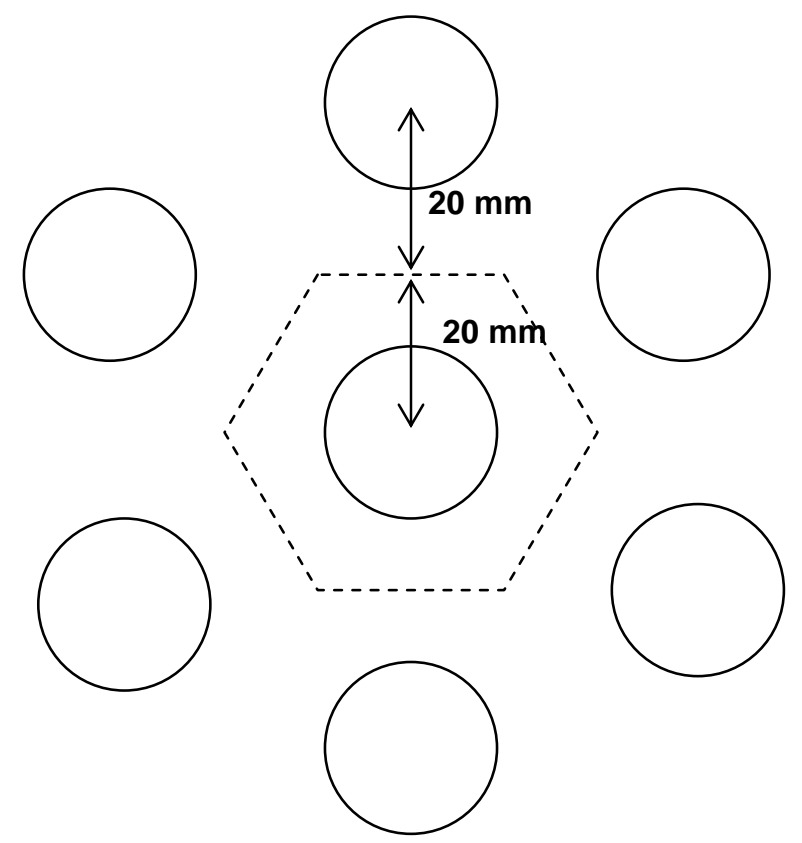

Figure 22. Area assigned to each jet.

For the slot jet, the fraction of inactive matrix material is calculated by

$$
\mathrm{F}=\frac{1}{\mathrm{x}_{\mathrm{p}}} \int_{0}^{\mathrm{x}_{\mathrm{p}}} \frac{[\mathrm{S}-\mathrm{b}(\mathrm{x})] \mathrm{L}}{\mathrm{SL}} \mathrm{dx}
$$

where $b(x)$ is the jet width, $x_{p}$ is the jet penetration depth, $S$ is the jet center-to-center spacing $(31.5 \mathrm{~mm})$, and $L$ is the jet length. A value of $69 \%$ is found for the LSMU plates with the slot jet generator. This compares to $47 \%$ for the round jets entering the LSMU regenerator and $55 \%$ for the round jets entering the $90 \%$ porous screen regenerator 
studied by Niu et al. ${ }^{2}$. The equivalent depth of inactive matrix for slot jets issuing into the LSMU is: $x_{p} / d_{h} \cdot \mathrm{F}$ $=10 \mathrm{x} 0.69=6.9$. Thus, matrix material to a depth of 6.9 hydraulic diameters is identified as inactive.

\section{Conclusions}

In the current study, in order to evaluate the performance of the regenerator in its acceptance of jets from mating heat exchangers, the jet penetration depth and active fraction are used.

Experimental measurements are taken to indicate how the jets (round jets and slot jets) grow with axial distance from the inlet within the LSMU plates. For the round jets, the jet penetration depth is the thickness of 8 LSMU plates $(63.5 \mathrm{~mm})$, which is about 13 times the hydraulic diameter of the LSMU plates. For the slot jets, the jet penetration depth is the thickness of 6 LSMU plates $(47.6 \mathrm{~mm})$, which is about 10 times the hydraulic diameter of the LSMU plates. For a regenerator of $75 \mathrm{~mm}$ ( 3 inches) long, a typical length of Stirling engine regenerator, the ratio of the jet penetration depth to the regenerator length is 0.028 for the round jets and 0.021 for the slot jets. These are very small numbers, indicating that the segmented-involute-foil regenerator has a very good performance for jet penetration. The equivalent depth of inactive matrix for each is about 6 or 7 hydraulic diameters. Measurements of these quantities made by others for jet penetration into a screen regenerator allow a comparison between screen regenerators and the LSMU geometry. The depth of jet penetration into a screen regenerator is 3.33 times the hydraulic diameter of the screen regenerator and the equivalent depth of inactive matrix is 1.8 hydraulic diameters. Thus, the LSMU geometry has a deeper jet penetration depth compared to screens and about 3.4 times as many hydraulic diameters of depth of inactive matrix.

\section{Acknowledgments}

We are grateful for sponsorship of this effort by the NASA Headquarters Science Mission Directorate (SMD) and the Radioisotope Power System (RPS) Program and for the support of the NASA Glenn Research Center (GRC) under NASA Contract NAS3-03124. Dr. Roy Tew of NASA-GRC is the Contracting Officer's Technical Representative. His guidance is greatly appreciated.

\section{References}

${ }^{1}$ Gedeon, D., "Modeling 2-D Jets Impinging on Stirling Regenerators," Proceedings of the $24^{\text {th }}$ Intersociety Energy Conversion Engineering Conference, 1989, pp. 2199-2203.

${ }^{2}$ Niu, Y., Simon, T. W., Ibrahim, M. B., Tew, R. C., and Gedeon, D., "Jet Penetration into a Stirling Engine Regenerator Matrix with Various Regenerator-Cooler Spacings," Paper \# AIAA-2003-6014, International Energy Conversion Engineering Conference, Portsmouth VA, 2003.

${ }^{3}$ Seume, J., Friedman, G., and Simon, T., "Fluid Mechanics Experiments in Oscillatory Flow, Volume I-Report," NASA Contractor Report 189127, March 1992.

${ }^{4}$ Sun, L., "Fluid Mechanics and Heat Transfer Experiments in the Large Scale Mock Up of the Microfabricated Stirling Engine Regenerator," Ph.D. Dissertation, Mechanical Engineering Dept., University of Minnesota, Minneapolis, MN, 2007.

${ }^{5}$ Gedeon, D., Private Communication, Jul. 8, 2005. 